\title{
Oridonin Inhibited the Tyrosine Kinase Activity and Induced Apoptosis in Human Epidermoid Carcinoma A431 Cells
}

\author{
Dan Li ${ }^{a, b}$ Li-Jun Wu, ${ }^{b}$ Shin-ichi Tashiro, ${ }^{c}$ Satoshi Onodera, ${ }^{c}$ and Takashi IkeJIMA ${ }^{*, a}$ \\ ${ }^{a}$ China-Japan Research Institute of Medical and Pharmaceutical Sciences, Shenyang Pharmaceutical University; \\ ${ }^{b}$ Department of Phytochemistry, Shenyang Pharmaceutical University; 103 Wenhua Road, Shenyang, 110016, P. R. China: \\ and ${ }^{c}$ Department of Clinical and Biomedical Science, Showa Pharmaceutical University; Tokyo 194-8543, Japan. \\ Received July 25, 2006; accepted November 15, 2006; published online November 20, 2006
}

\begin{abstract}
Oridonin, an active component isolated from the plant Rabdosia rubescens, has been reported to exhibit antitumor effects, but little is known about its molecular mechanism of action. In this study, we first investigated the mechanism involved in oridonin-induced cell death in human epidermoid carcinoma A431 cells, which overexpress epidermal growth factor receptor (EGFR). After treatment with various doses of oridonin for $24 \mathrm{~h}$, the majority of A431 cells underwent apoptosis in a time- and dose-dependent manner as measured by an LDH activity-based assay. Treatment with oridonin at various concentrations for $24 \mathrm{~h}$ caused significant inhibition on the total tyrosine kinase activities and downregulation of EGFR expression or EGFR phosphorylation. Oridonin significantly affected the localization of EGFR and phosphorylated EGFR on the cell membrane. However, genistein (a well-known tyrosine kinase inhibitor) did not induce apoptotic A431 cell death. Importantly, oridonin exhibited much stronger inhibitory effect on the total tyrosine kinase activities or EGFR tyrosine phosphorylation as well as much stronger suppression on EGFR and phosphorylated EGFR localization than genistein in A431 cells. Taken together, oridonin exerted a potential inhibitory effect on the tyrosine kinase activity of A431 cells. The decrease in the tyrosine kinase activity and the blockage of EGFR tyrosine phosphorylation might be one of the causes of oridonin-induced A431 cell death.
\end{abstract}

Key words oridonin; epidermal growth factor receptor; A431 cell; apoptosis; tyrosine kinase; genistein

Herbal medicine, Donglingcao (Rabdosia rubescens), has been traditionally used in China. Diterpenoids are the major constituent of R. rubescens. Oridonin ${ }^{1)}$ (Fig. 1) is one of the diterpenoids isolated from $R$. rubescens, which has various pharmacological and physiological effects such as antiinflammation, anti-bacteria and anti-tumor effects, ${ }^{2-4)}$ and has been used for the treatment of human cancer, especially esophageal carcinoma. ${ }^{5)}$ However, the mechanism of oridonin-induced A431 cell death remains unclear.

Protein phosphorylation or dephosphorylation is an important regulatory mechanism in the action of many growth factors and hormones, which can transmit their messages through activation of cellular protein tyrosine kinases (PTKs). Moreover, the expression level of PTKs, including several membrane-associated oncogene products, is elevated in tumor cells. ${ }^{6-10)}$ This upregulation is associated with the development of various types of cancers. Therefore, it is important to inhibit protein tyrosine kinase activities or their phosphorylation for suppression of uncontrolled tumor cell growth. ${ }^{11)}$

PTKs can be divided into two classes: the transmembrane receptor tyrosine kinases (RTKs) and non-receptor tyrosine kinases (NRTKs). Epidermal growth factor receptor (EGFR) is one of the transmembrane receptor tyrosine kinases, overexpress of which has been found in a number of human can-

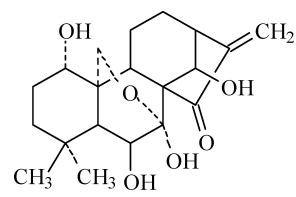

Fig. 1. Chemical Structure of Oridonin cers, including colon, lung and bladder cancers. ${ }^{12)}$ The mature EGFR is a $170-\mathrm{kDa}$ transmembrane glycoprotein ${ }^{13,14)}$ and it is activated by dimerization upon binding its ligand, EGF, and subsequently receptor tyrosine is phosphorylated in the cytoplasmic tail. This event initiates the recruitment and phosphorylation of several intracellular substrates (including PLC $\gamma 1$, shc, Grb2, RasGAP, Src, Nck etc. ${ }^{15-17)}$ ), then leading to mitogenic signaling and other cellular events. ${ }^{18,19)}$ Growing evidences have demonstrated that selective inhibition of receptor tyrosine kinase activity becomes more important in treatment human cancers. Therefore, in this study, we chose human epidermoid carcinoma A431 cells, which overexpress EGFR as the source of tyrosine kinase.

Genistein is a natural isoflavone product that was first isolated from Pseudomonas sp, which targets the ATP-binding site of protein tyrosine kinase. And it is a well known potential inhibitor of PTKs, inhibiting EGFR autophosphorylation and activities of src kinase, abl kinase and other PTKs. ${ }^{20-24)}$ At present, some other flavonoids, such as luteolin and quercetin, have also been found to suppress the activity of protein tyrosine kinases. ${ }^{25,26)}$ But it has never been reported that diterpenoids that possess anti-tumor activity have any significant effect on the tyrosine kinase activity.

It is well known that the majority of cell death signals pass through two distinct pathways: apoptosis and necrosis. Many natural products have been reported to exert their antitumor effects by induction of cancer cell apoptosis. ${ }^{27)}$ Apoptosis is a cell-autonomous death process that requires the active participation of endogenous cellular enzymes and oncogene expression. Morphologically, this process is characterized by a dramatic execution phase that induces loss of cell volume, plasma membrane blebbing, nuclear chromatin condensation and fragmentation, DNA degradation and formation of apop- 
totic bodies. ${ }^{28)}$

In this study, we demonstrated that oridonin induced A431 cell death through distinct mechanisms and pathways, including apoptosis and necrosis. The mechanism of oridonin-induced A431 cell death might be associated with inhibiting its total tyrosine kinase activity and blocking EGFR tyrosine phosphorylation.

\section{MATERIALS AND METHODS}

Reagent Oridonin was obtained from the Beijing Institute of Biological Products (Beijing China). The structure of oridonin was assigned by comparing the chemical and spectral data $\left({ }^{1} \mathrm{H}-,{ }^{13} \mathrm{C}\right.$-NMR $)$ with those reported in the literature. ${ }^{29)}$ The purity of the oridonin was measured by HPLC and determined to be 99.4\%. 3-(4,5-Dimethylthiazol-2-yl)2,5-diphenylterazolium bromide (MTT), Ribonuclease (RNase), proteinase $\mathrm{K}$, propidium iodide (PI) and Hoechst 33258 were purchased from Sigma Chemical (St. Louis, MO, U.S.A.). Pan-caspase inhibitor (z-VAD-fmk), polyclonal antibodies against EGFR, phospho-EGFR and horseradish peroxidase-conjugated secondary antibodies (goat-anti-rabbit and bovine-anti-goat) were obtained from Santa Cruz Biotechnology (Santa Cruz, CA, U.S.A.). Tyrosine kinase activity assay kit was from Chemicon International (Temecula, CA, U.S.A.). Human EGF (epidermal growth factor) was from Pepro Tech (Rocky Hill, NJ, U.S.A.).

Cell Culture Human epidermoid carcinoma A431 cell line was obtained from American Type Culture Collection (ATCC) (Manassas, VA, U.S.A.). Cells were cultured in Ham's F-12 medium (Hyclone, Logan, UT, U.S.A.) supplemented with $10 \%$ heated inactivated fetal bovine serum (Beijing Yuanheng Shengma Research Institution of Biotechnology, Beijing, China), $100 \mu \mathrm{g} / \mathrm{ml}$ streptomycin, $100 \mathrm{U} / \mathrm{ml}$ penicillin, and $0.03 \%$ L-glutamine and maintained at $37^{\circ} \mathrm{C}$ with $5 \% \mathrm{CO}_{2}$ in a humidified atmosphere.

Cytotoxity Assay A431 cells were incubated at $3 \times 10^{4}$ cells per well in 96-well plates (NUNC, Roskilde, Denmark). Then the cells were treated with oridonin at various doses for $6,12,24$ or $36 \mathrm{~h}$. Cell growth was measured with a plate reader (TECAN SPECTRA, Wetzlar, Germany) by 3-(4,5Dimethylthiazol-2-yl)-2,5-diphenylterazolium bromide (MTT) assay. ${ }^{5)}$ The percentage of cell growth inhibition was calculated as follows:

cell death $(\%)=\left[A_{492}(\right.$ control $)-A_{492}($ oridonin $\left.)\right] / A_{492}($ control $) \times 100$

Observation of Morphologic Changes A431 cells in Ham's F-12 containing 10\% FBS were seeded into 6-well culture plates and cultured for 12 or $24 \mathrm{~h}$. Control cultures were treated with the $0.05 \%$ dimethyl sulfoxide (DMSO). Oridonin $(20 \mu \mathrm{M})$ was added to the cell culture and the cellular morphology was observed using phase contrast microscopy (Leica, Wetzlar, Germany).

Nuclear Damage Observed by Hoechst 33258 Staining Apoptotic nuclear morphology was assessed using Hoechst 33258 staining. The cells were fixed with $3.7 \%$ paraformaldelyde for $30 \mathrm{~min}$ at room temperature, and then washed and stained with $167 \mu \mathrm{M}$ Hoechst 33258 at $37^{\circ} \mathrm{C}$ for $30 \mathrm{~min}$. The cells were again washed and resuspended in PBS for morphologic observation using a fluorescent microscope (Olympus, Tokyo, Japan).
LDH Activity-Based Cytotoxicity Assays LDH (lactate dehydrogenase) activity was assessed using a standardized kinetic determination kit (Zhongsheng LDH kit, Beijing, China). LDH activity was measured in both floating dead cells and viable adherent cells. The floating cells were collected from culture medium by centrifugation $(240 \times \boldsymbol{g})$ at $4{ }^{\circ} \mathrm{C}$ for $5 \mathrm{~min}$, and the LDH content from the pellets was used as an index of apoptotic cell death (LDHp). ${ }^{5)}$ The LDH released in the culture supernatant (extracellular LDH, or LDHe) was used as an index of necrotic death, and the LDH present in the adherent viable cells as intracellular LDH (LDHi). The percentage of apoptotic and necrotic cell death was calculated as follows:

\footnotetext{
$\%$ apoptosis $=\mathrm{LDHp} /(\mathrm{LDHp}+\mathrm{LDHi}+\mathrm{LDHe}) \times 100$

$\%$ necrosis $=\mathrm{LDHe} /(\mathrm{LDHp}+\mathrm{LDHi}+\mathrm{LDHe}) \times 100$
}

Tyrosine Kinase Activity Assay A431 cells were treated with lysis buffer (RIPA buffer: $50 \mathrm{~mm}$ Tris- $\mathrm{HCl}(\mathrm{pH}$ $8.0), 150 \mathrm{~mm} \mathrm{NaCl}, 0.5 \mathrm{~mm}$ EDTA, 1 mм DTT, $1 \%$ NP-40, $0.5 \%$ sodium deoxycholate, $0.1 \%$ SDS, $100 \mu \mathrm{g} / \mathrm{ml}$ PMSF, $1 \mu \mathrm{g} / \mathrm{ml}$ aprotinin, $2 \mu \mathrm{g} / \mathrm{ml}$ leupeptin, $100 \mu \mathrm{m}$ sodium vanadate) on ice for $10 \mathrm{~min}$. Then mixed with $5 \times$ assay buffer (20 mM HEPES-KOH (pH 7.4), $10 \mathrm{~mm} \mathrm{MgCl}_{2}, 3 \mathrm{~mm} \mathrm{MnCl}_{2}$, $0.1 \mathrm{~mm} \mathrm{Na}_{3} \mathrm{VO}_{4}, 1 \mathrm{~mm}$ DTT) before $10 \mu \mathrm{l}$ of $5 \times \mathrm{ATP} / \mathrm{MgCl}_{2}$ solution was added. After reactions the absorbance of each microwell were read through ELISA at $450 \mathrm{~nm}$.

Flowcytometric Analysis ${ }^{30)}$ A431 cells $\left(1 \times 10^{6}\right)$ were harvested and washed once in cold phosphate-buffered saline (PBS). Cell pellets were fixed in $70 \%$ ethanol and washed in cold PBS. Then the pellets were suspended in $1 \mathrm{ml}$ of PI solution containing $50 \mu \mathrm{g} / \mathrm{ml}$ of PI, $1 \mathrm{mg} / \mathrm{ml}$ RNase A and $0.1 \%$ (w/v) Triton X-100 in sodium citrate $(3.8 \mathrm{~mm})$, followed by incubation on ice in the dark condition for $30 \mathrm{~min}$. Samples were analyzed by FACScan flow cytometer (Becton Dickinson, Franklin Lakes, NJ, U.S.A.).

DNA Fragmentation Assay A431 cells $\left(1 \times 10^{6}\right)$ were collected by centrifugation at $1000 \times \boldsymbol{g}$ for $5 \mathrm{~min}$, and washed with PBS. The cells were pelleted and suspended in $100 \mu \mathrm{l}$ cell lysis buffer $(10 \mathrm{mmol} / 1$ Tris- $\mathrm{HCl}(\mathrm{pH} 7.4), 10 \mathrm{mmol} / 1$ EDTA (pH 8.0) and $0.5 \%$ Triton X-100), and kept at $4{ }^{\circ} \mathrm{C}$ for $10 \mathrm{~min}$. The lysate was centrifuged at $15000 \times \mathbf{g}$ for $20 \mathrm{~min}$. The supernatant was incubated with RNase A $(20 \mu \mathrm{g} / \mu \mathrm{l})$ at $37^{\circ} \mathrm{C}$ for $1 \mathrm{~h}$ and then incubated with proteinase $\mathrm{K}(20 \mu \mathrm{g} /$ $\mu \mathrm{l})$ at $37^{\circ} \mathrm{C}$ for $1 \mathrm{~h}$. Then the supernatant was again mixed with $0.5 \mathrm{M} \mathrm{NaCl}(20 \mu \mathrm{l})$ and $50 \%$ isopropanol $(120 \mu \mathrm{l})$ at $-20^{\circ} \mathrm{C}$ overnight, followed by centrifugation at $15000 \times \boldsymbol{g}$ for $15 \mathrm{~min}$. After drying, DNA was dissolved in TE buffer, PH 7.8 [10 mm Tris-HCl (pH 7.4), 10 mm EDTA (pH 8.0)], separated by $2 \%$ agarose gel electrophoresis at $100 \mathrm{~V}$ for $40 \mathrm{~min}$ and stained with $0.1 \mathrm{mg} / \mathrm{l}$ ethidium bromide.

Immunostaining Immunostaining for EGFR using horseradish peroxidase (HRP). A431 cells were fixed with $4 \%$ paraformaldehyde for $15 \mathrm{~min}$ and permeabilized with $0.2 \%$ Triton X-100, and then processed for immunostaining. In brief, cells were incubated with monoclonal antibody that recognizes EGFR and then with a secondary antibody conjugated to horseradish peroxidase (HRP). After $2 \mathrm{~h}$, the cells were stained with 3,3-diaminobenzidine tetrahydrochloride (DAB) as the HRP substrate. ${ }^{31)}$

Preparation of Cytosolic Extracts for Examination of EGFR To examine the expression of EGFR, lysates were 
prepared. A431 cells washed twice with PBS, and lysed in ice-cold lysis buffer containing $20 \mathrm{~mm}$ Tris- $\mathrm{HCl}(\mathrm{pH} \mathrm{7.5)}$, $1 \%$ Triton X-100, 1 mм EDTA, 1 mм EGTA, 10 mм $\beta$-mercaptoethanol, $1 \mathrm{~mm}$ sodium orthovanadate, $10 \mu \mathrm{g} / \mathrm{ml}$ leupeptin, $1 \mathrm{~mm}$ phenylmethyl-sulfonylfluoride (PMSF). ${ }^{32)}$ After 60 min of incubation on ice, cells were swelled, and then centrifuged at $12000 \times \boldsymbol{g}$ for $20 \mathrm{~min}$; the supernatant was stored at $-80^{\circ} \mathrm{C}$ until analysis.

Westernblot Analysis A431 cells were treated with oridonin of different concentrations. Both adherent and floating cells were collected, and then Western blot analysis was carried out as previously described with some modification. The protein content was determined by a protein assay reagent (Bio-Rad Laboraories, Hercules, CA, U.S.A.). The protein lysates $(20 \mu \mathrm{l})$ were separated by electrophoresis in $7.5 \%$ SDS polyacrylamide gel and blotted onto a nitrocellulose membrane. ${ }^{33)}$ Proteins were detected using polyclonal antibody and visualized using anti-rabbit or anti-goat IgG conjugated with HRP and DAB as the HRP substrate. Protein concentration was determined by the Folin assay.

Statistical Analysis of the Data The data are expressed as means \pm S.D. Statistical comparisons were made by Student's $t$-test. $p<0.05$ was considered significant.

\section{RESULTS}

Effect of EGF on the Total Tyrosine Kinase Activity or EGFR Autophosphorylation of A431 Cells The cells

$\mathbf{A}$
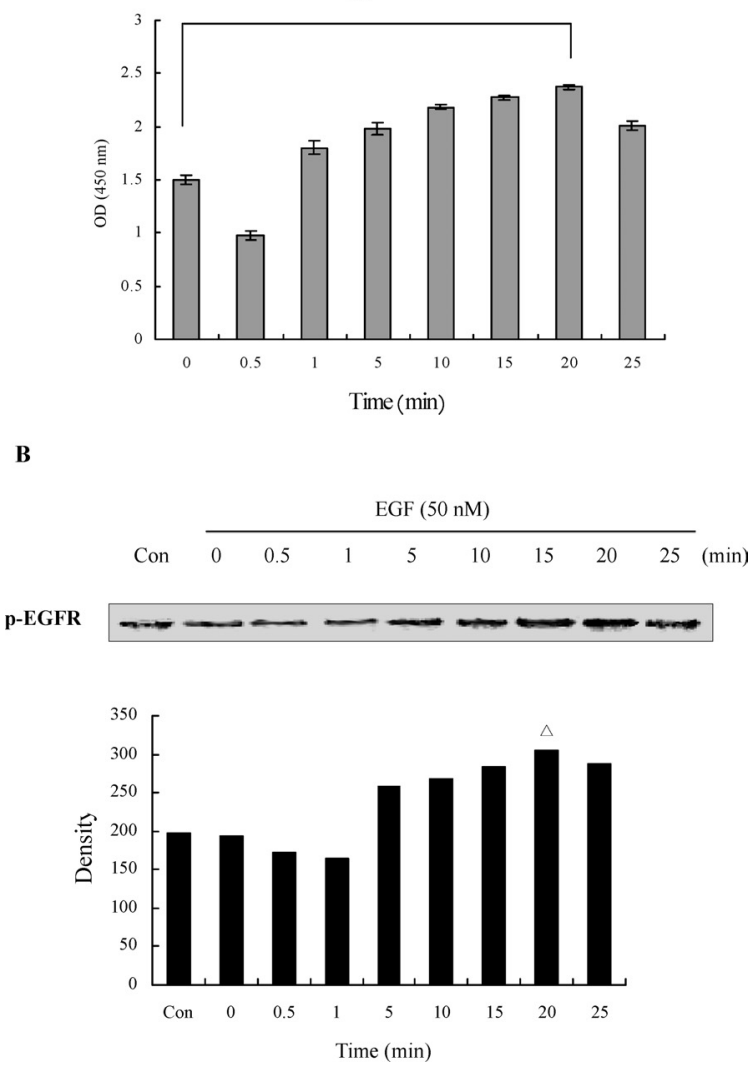

Fig. 2. Effect of EGF on the Total Tyrosine Kinase Activity of A431 Cells

(A) After incubation with $15 \mathrm{nM}$ EGF for different time periods, the total kinase activity of the cellular proteins was measured by ELISA at $450 \mathrm{~nm}$. (B) Expression of phosphorylated EGFR was analyzed by Western blotting. $* * p<0.01$. Triangles indicate significant difference between the cells treated with vehicle and EGF-stimulated cells. were treated with $15 \mathrm{~nm}$ EGF at different time points, and then the whole cell lysate were detected by tyrosine kinase kit. Results showed $15 \mathrm{~nm}$ EGF began to activate the tyrosine kinase activities at $1 \mathrm{~min}$, and then reached the peak at $20 \mathrm{~min}$ (Fig. 2A), followed by slight declining. We further analysed the phosphorylation pattern of EGFR by Western blot analysis (Fig. 2B). The time courses of EGFR activation were consistent with the total tyrosine kinase activities, and in response to EGF for $20 \mathrm{~min}$, maximum EGFR activation occurred in the presence of $15 \mathrm{~nm}$ EGF.

Inhibitory Effect of Oridonin or Genistein on Total Tyrosine Kinase Activities of A431 Cells The total kinase activities of the cellular proteins were measured by tyrosine kinase activity assay kit. In response to various doses of genistein or oridonin for $24 \mathrm{~h}$, the total tyrosine kinase activities of A431 cells were measured by ELISA at $450 \mathrm{~nm}$ (Fig. $3 \mathrm{~A})$. The addition of EGF to the reaction mixture resulted in a $21.51 \pm 3.1 \%$ increase in the total tyrosine kinase activities, while $20 \mu \mathrm{M}$ oridonin and $20 \mu \mathrm{M}$ genistein decreased the tyrosine phosphorylation by $64.6 \pm 5.7 \%$ and $42.4 \pm 6.2 \%$, respectively, as compared with the control values.

However, once cells undergo apoptosis, the total cell number may be reduced. Under this condition, the total tyrosine kinase activity may also be downregulated. In order to confirm that the downregulation of the total tyrosine kinase activity was induced by oridonin, but not by the decrease of cell number, pan-caspase inhibitor (z-VAD-fmk) was performed. As shown in Fig. 3B, although reduction of apoptotic ratio affected the downregulation of oridonin-induced

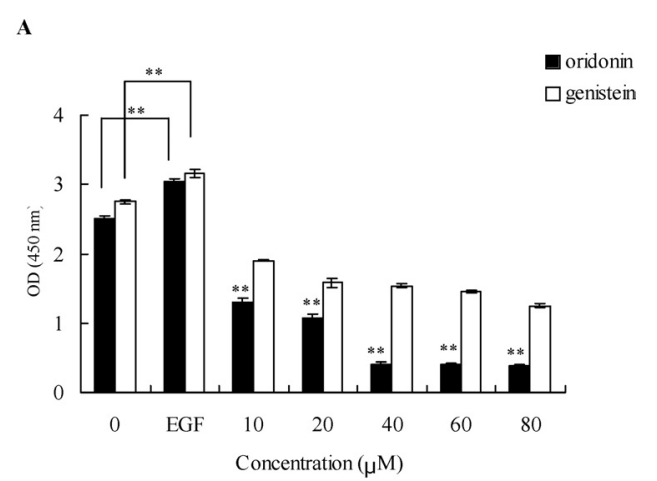

B

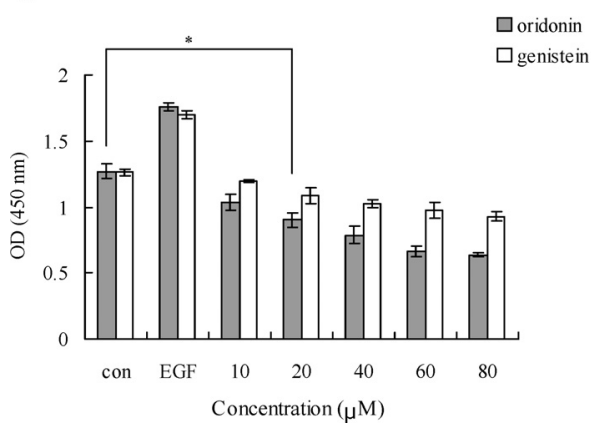

Fig. 3. Effects of Oridonin and Genistein on Total Tyrosine Kinase Activities of A431 Cells

(A) A431 cells were pretreated with $15 \mathrm{nM}$ EGF for 20 min before various concentrations of oridonin or genistein were added. After $24 \mathrm{~h}$, optical density values $(450 \mathrm{~nm})$ were measured by tyrosine kinase activity assay kit. $* * p<0.01, \mathbf{\square}$ : oridonin, $\square$ : genistein. (B) The cells were cultured in the absence or presence of the pan-caspase inhibitor ( $\mathrm{z}$-VAD-fmk) for $1 \mathrm{~h}$ prior to addition of oridonin or genistein, and then incubated for $24 \mathrm{~h}$. Striated and white bars represent oridonin plus caspase inhibitor and genistein plus caspase inhibitor, respectively. $\bar{x} \pm \mathrm{s}, n=3, * p<0.05$. 
tyrosine kinase activity in some extent, oridonin treatment group still exerted stronger inhibitory effect on the total tyrosine kinase activity than genistein treatment group. All these results showed that the same dose of oridonin exhibited a much stronger inhibitory effect on the total tyrosine kinase activities than genistein.

EGF-Induced Tyrosine Kinase Phosphorylation Was Inhibited by Oridonin and Genistein As it is well known, A431 cells express high levels of epidermal growth factor receptor (EGFR), which is a member of the receptor tyrosine kinase family and plays an important role in division and growth of tumor cells. ${ }^{34,35)}$ The blockage of EGFR phosphorylation can also be responsible for tumor growth inhibition. Therefore, the expression level of EGFR (Fig. 4A) and EGFR phosphorylation (Fig. 4B) were further examined in the presence of different concentration of oridonin or genistein by Western blot analysis. The results showed that oridonin significantly decreased EGF-augmented expression of phosphorylated EGFR, whereas genistein did not show significant change in EGFR tyrosine phosphorylation in A431

$\mathbf{A}$
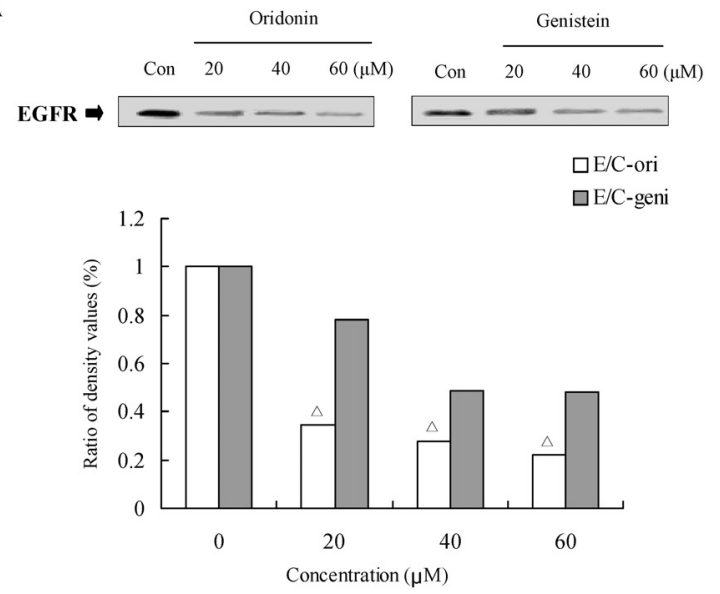

B
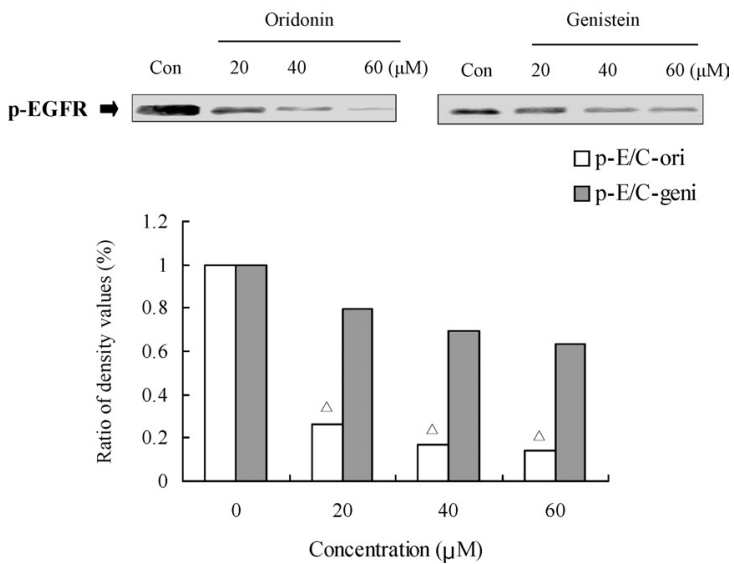

Fig. 4. Inhibitory Effect of Oridonin or Genistein on the Expression of EGFR or Phosphorylated EGFR of A431 Cells

A431 cells were treated with $15 \mathrm{nM}$ EGF for 20 min prior to the administration of various doses of oridonin or genistein for $24 \mathrm{~h}$, and the expression of EGFR (A) or phosphorylated EGFR (B) were detected by Western blot analysis. Oridonin: 20, 40 and $60 \mu \mathrm{M}$. Genistein: 20, 40 and $60 \mu \mathrm{m}$. E/C-ori: (band density of EGFR)/(band density of Control) induced by various concentrations of oridonin. E/C-geni: (band density of EGFR)/(band density of Control) induced by various concentrations of genistein. pE/C-ori: (band density of phosphorylated EGFR)/(band density of Control) induced by various concentrations of oridonin. p-E/C-geni: (band density of phosphorylated EGFR)/(band density of Control) induced by various concentrations of genistein). Triangles indicate significant difference between cells treated with genistein- and oridonin-treated cells. cells. Although we did not elucidate whether downregulation of protein expression level is consistent with the level of mRNA, we speculate that there may exist following two results about the expression of EGFR mRNA. First, if oridonin inhibits EGFR on the gene level, downregulation of mRNA level might occur as a consequence of disrupting transcription of mRNA, resulting in decreased mRNA to EGFR protein translation. Second, this decrease in EGFR protein expression, without a change in mRNA levels, might occur, since oridonin might not affect transcription of mRNA, but interfere translation or downregulation of stability of EGFR proteins. All these may lead to the downregulation of EGFR expression.

EGFR Immunostaining in A431 Cells To confirm the above observations that EGFR or phosphorylated EGFR protein expression was downregulated in oridonin treated cells, we carried out immunostaining for EGFR and p-EGFR on A431 cells. Consistent with the results of Western blot analysis, in genistein-treated group, the strong immunoreactivity of cell membrane was not reduced compared with control (Figs. 5A-a, 5A-b; 5B-a, 5B-b), whereas in the group of oridonin treatment, there showed weaker degree of staining for EGFR (Fig. 5C-a) as well as phosphorylated EGFR (5C-b). These results indicated that oridonin affect the localization of EGFR on the cell membrane.

Effect of Oridonin on the Growth of A431 Cells It has been suggested that the extent of tyrosine phosphorylation is an important indicator for cell growth, thus we examined the effects of oridonin on the growth of A431 cells. Incubation of A431 cells by different doses of oridonin $(5,20,40$ or 80 $\mu \mathrm{M})$ for different time periods $(6,12,24$ or $36 \mathrm{~h})$ resulted in a significant increase in the death rate (Fig. 6), demonstrating that oridonin-induced A431 cell death was in a time- and dose-dependent manner.

Oridonin Induced A431 Cell Death by Affecting the Balance Between Apoptosis and Necrosis To determine whether oridonin-induced A431 cell death was caused by apoptosis, the morphologic changes were confirmed by Hoechst33258 staining of cell nuclei (Fig. 7). In the control group, cells had faintly stained nuclei (Fig. 7A), whereas apoptotic condensed nuclei stained brightly for fluorescence microscopy by $10 \mu \mathrm{M}$ oridonin treatment (Fig. 7B), and apoptotic characteristics were more significant by $20 \mu \mathrm{M}$ oridonin (Fig. 7C). Consistent with the above results of Hoechst33258 staining, morphologic changes were obvious in $20 \mu \mathrm{M}$ oridonin-treated cells by phase contrast microscopy (Figs. 7E, F). Oridonin induced A431 cell apoptosis in a time- and dose-dependent manner.

To further characterize oridonin-induced A431 cell death, the ratio of LDH release from viable cells, floating dead cells and the culture medium were compared (Fig. 8). The number of apoptotic cells was upregulated, with lower number of necrotic cells, after progressively increasing concentration of oridonin, demonstrating that major cause of oridonin-induced A431 cell death was apoptosis.

Mechanism of Genistein on the Growth-Inhibition of A431 Cells Genistein, a specific inhibitor of PTK, was found to inhibit cell growth and induce differentiation in human HL-60 and K562 leukemia cells. ${ }^{36)}$ In this study, the growth-inhibitory effects of genistein on A431 cells were examined by culturing the cells with $5-80 \mu \mathrm{M}$ genistein for 
A
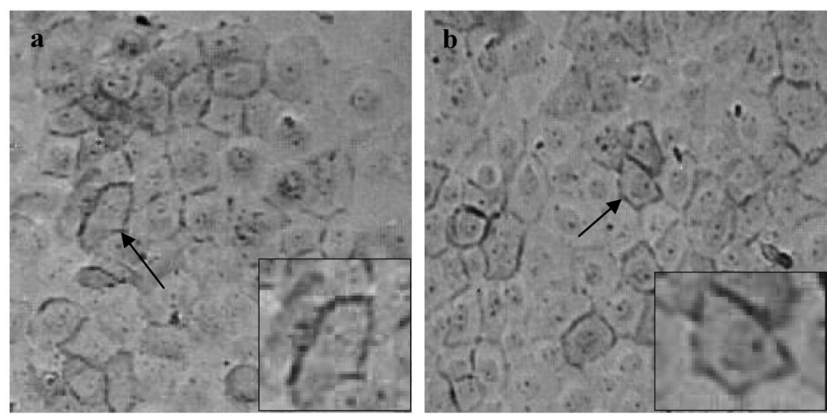

B
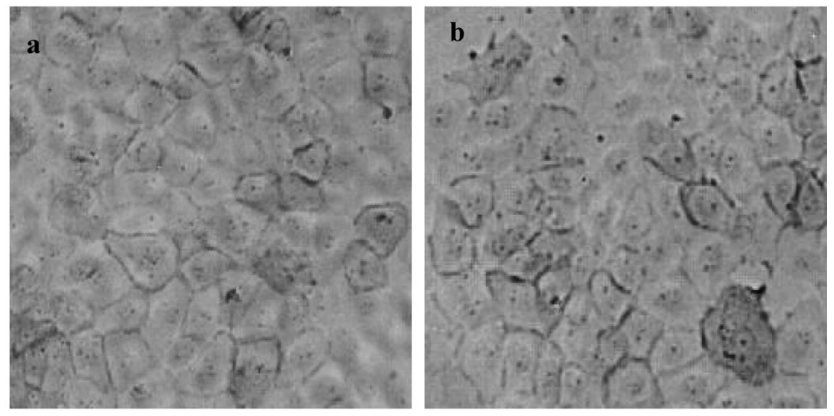

C
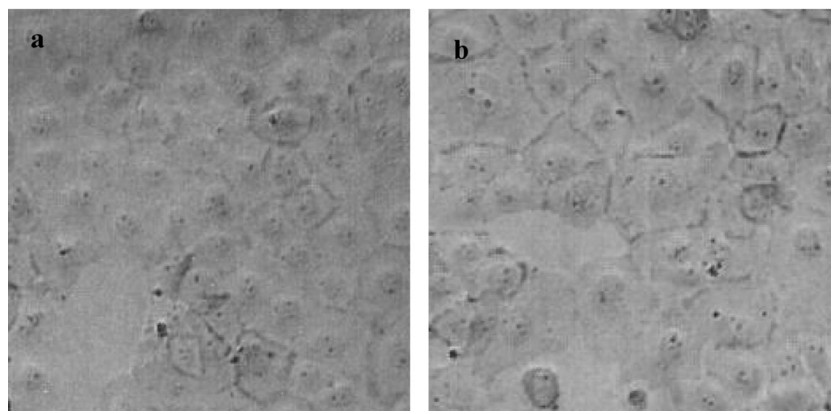

Fig. 5. Immunostaining for EGFR in A431 Cells

(A) A431 cells were treated with vehicle only. The cells were treated with genistein (B) and oridonin $(20 \mu \mathrm{M})(C)$, respectively. Note the red immunostaining for EGFR, $\mathrm{p}-$ EGFR $(\times 200$ magnification). a: EGFR, b: p-EGFR. Arrows indicate the cell membrane stained with polyclonal anti-EGFR (A-a) or anti-p-EGFR (A-b) antibody.

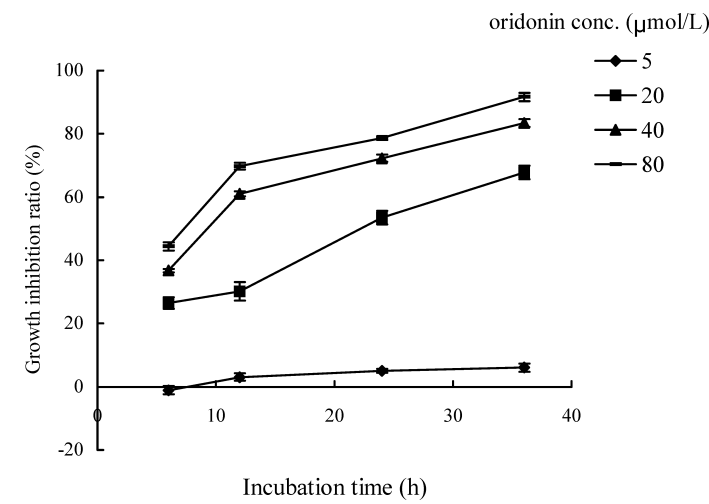

Fig. 6. Effect of Oridonin on the Growth of A431 Cells

A431 cells $\left(2 \times 10^{4}\right.$ cells/well $)$ were treated with various doses of oridonin for 6,12 , 24 or $36 \mathrm{~h}$. Cell numbers were measured by MTT assay and growth inhibition was calculated. $n=3$, mean \pm S.D.
A
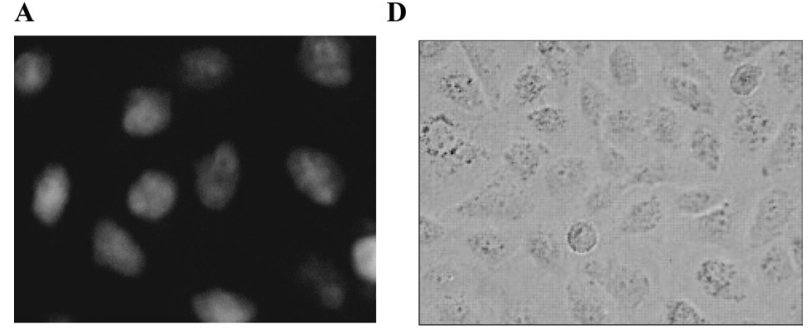

B
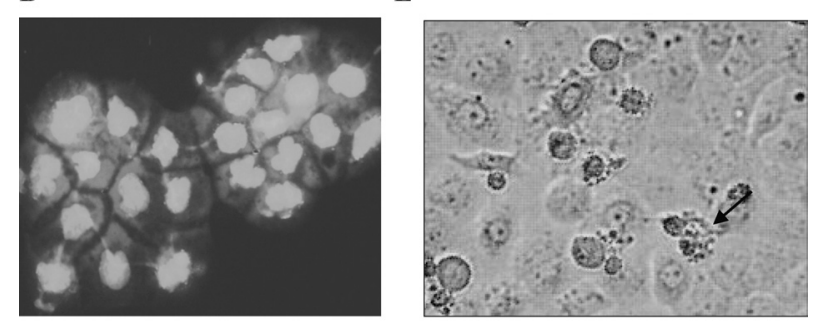

C

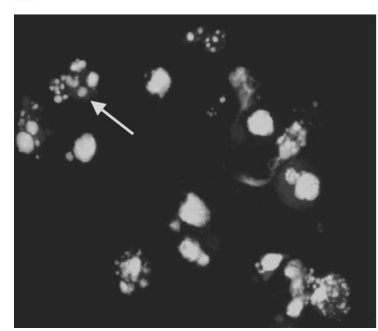

F

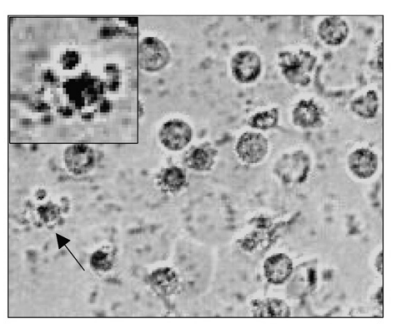

Fig. 7. Oridonin-Induced Morphologic Changes in A431 Cells

A431 cells were incubated in medium alone (A) or medium containing $10 \mu \mathrm{M}$ oridonin (B), or $20 \mu \mathrm{m}$ oridonin (C) for $24 \mathrm{~h}$, and then the cells were stained with Hoechst 33258 and observed at $\times 200$ magnification. The cells were incubated in 6-well culture plates. Changes in cellular morphology were examined at $12 \mathrm{~h}(\mathrm{E})$ or for $24 \mathrm{~h}(\mathrm{~F})$ in the absence (D) or presence of oridonin $20 \mu_{\mathrm{M}}(\times 200$ magnification). Arrows indicate significant difference between cells treated with vehicle and oridonin-treated cells.

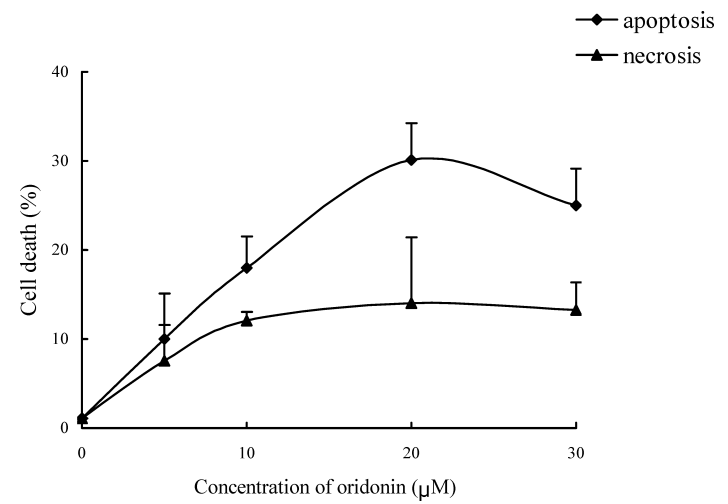

Fig. 8. Oridonin Induced A431 Cell Death Was Characterized by Apoptosis and Necrosis

Cells treated with various doses of oridonin ( $0.05 \%$ DMSO $(0), 5,10,20$ or $30 \mu \mathrm{M})$ for $24 \mathrm{~h}$ were measured by LDH activity-based assay. ( $\bullet$ : apoptosis, $\boldsymbol{\Delta}$ : necrosis). Data are mean \pm S.D. (bars) from 3 independent experiments.

$24 \mathrm{~h}$. Results showed that genistein exhibited a slight inhibitory effects on A431 cell growth (Fig. 9A).

Since genistein has been shown to induce apoptotic cell death, ${ }^{37)}$ flowcytometric analysis was further carried out. Neither in negative control nor in genistein-treated group, the cells at apoptotic subdipoid peak was observed (Fig. 9B), consistent with DNA fragmentation analysis (Fig. 9C, lane C). Smear-like DNA degradation was observed after incubation with $20 \mu \mathrm{M}$ genistein. But in the presence of $20 \mu \mathrm{M}$ ori- 

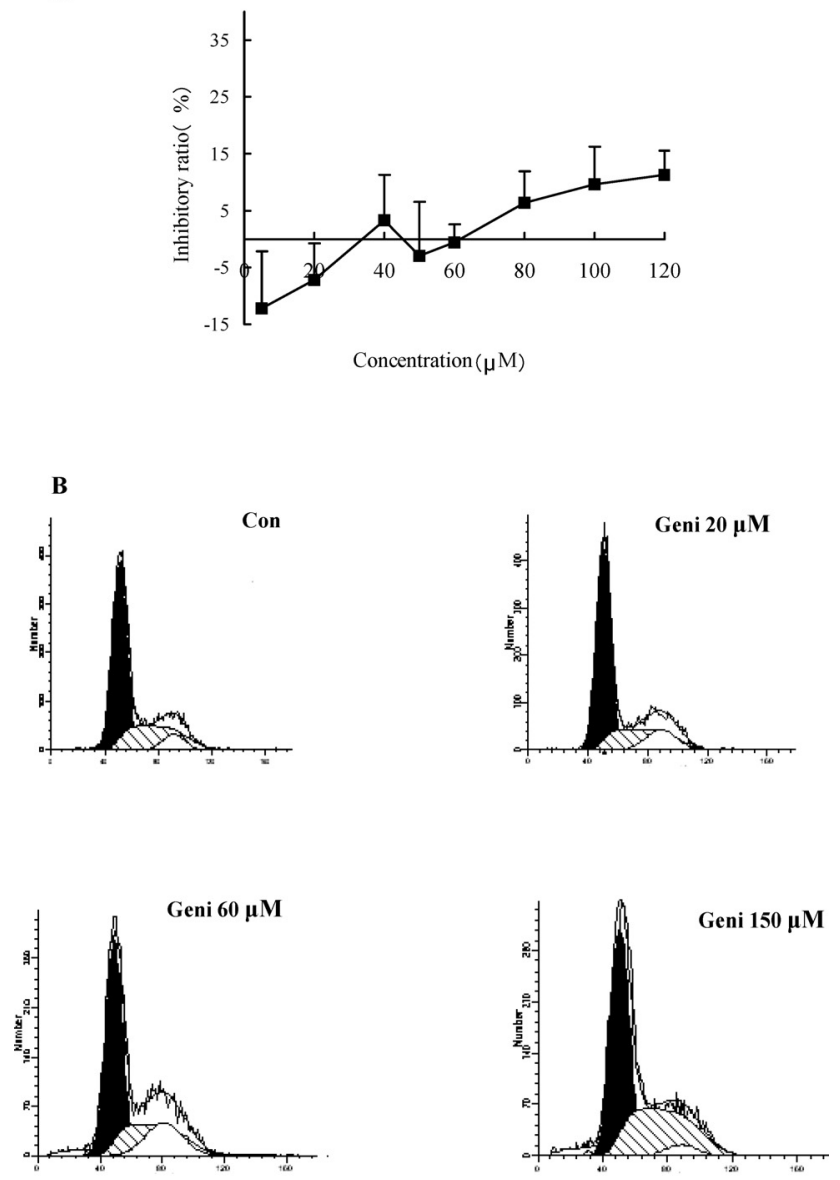

C

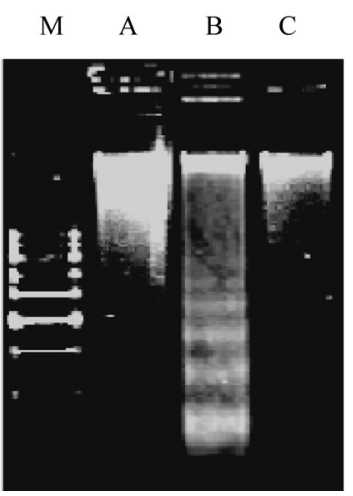

Fig. 9. Characterization of Genistein-Induced Growth Inhibition

(A) A431 Cells $\left(2 \times 10^{4}\right.$ cells/well) were treated with various doses of genistein (5$80 \mu \mathrm{M})$ for $24 \mathrm{~h}$. (B) After treatment with different doses of genistein $(20,60,150 \mu \mathrm{M})$ for $24 \mathrm{~h}$, the cells were washed by PBS and stained with PI followed by flowcytometric analysis. Con: control, Geni, genistein. (C) The cells were treated with $20 \mu \mathrm{M}$ oridonin or $20 \mu \mathrm{M}$ genistein for $24 \mathrm{~h}$. Then agarose gel electrophoresis was conducted. M: marker, lane A: medium, lane B: $20 \mu \mathrm{M}$ oridonin, lane C: $20 \mu \mathrm{M}$ genistein.

donin, A431 cells exhibited a loss of DNA integrity, showing a typical ladder pattern of multiples of $180-200$ base pairs, characteristic of apoptosis (Fig. 9C, lane B). These phenomena demonstrated that genistein might not induce apoptotic cell death in A431 cells, although it reduced the total tyrosine kinase activity and partially inhibit EGFR tyrosine phosphorylation.

\section{DISCUSSION}

As reported previously, oridonin, which is one of diterpenoids, could induce apoptosis in many human cell lines. In this study, it was first proposed that oridonin induced apoptosis of A431 cells, as well as with a strong potency to inhibit total tyrosine kinase activity and downregulate EGFR phosphorylation. These observations indicate that oridonin-induced apoptosis might be via inhibiting the total tyrosine kinase activity and blocking EGFR tyrosine phosphorylation.

PTKs activate multiple signaling pathways pivotal to cell division and survival. Therefore, inhibiting cellular protein tyrosine kinase activity correlates with growth inhibition in many tumor cells. ${ }^{38)}$ EGFR is one of the receptor protein tyrosine kinases. The binding of EGF to the extracellular domain of EGFR induces an increase in tyrosine kinase activity as well as the consequent phosphorylation and activation of its signal transduction components, such as in A431 cells. ${ }^{26)}$ In this study, the total tyrosine kinase activity was measured by administration of oridonin or genistein for $24 \mathrm{~h}$. Oridonin possess a much stronger potency to inhibit the total tyrosine kinase activity compared with genistein. Moreover, there was a significant growth inhibition at the doses ranging from oridonin 5 to $80 \mu \mathrm{M}$, compared with the medium control group. This indicates that oridonin-induced the inhibition of total tyrosine activity is associated with growth-inhibition in oridonin-treated A431 cells.

It has been reported that changes in the phosphorylation levels of certain proteins, such as EGFR, inhibit uncontrolled tumor cell growth. ${ }^{39)}$ Therefore, agents that inhibit EGFR tyrosine kinase activity may have the potential in the prevention of tumor cell proliferation. Administration of EGF to A431 cells caused a significant increase in EGFR tyrosine phosphorylation. But EGF-augmented EGFR tyrosine phosphorylation was markedly suppressed by oridonin but not by genistein, indicating that oridonin-induced the blockage of EGFR tyrosine phosphorylation might be tightly linked to the inhibition of the total tyrosine kinase activities.

Strong EGFR immunoreactivity in the some tumor cell membrane has been reported, and this suggests that EGFR might participate in the angiogenesis of tumor. ${ }^{40)}$ In this study, oridonin significantly reduced the strong immunoreactivity of EGFR or phosphorylated EGFR on the cell membrane as compared to control, which affected EGFR localization and its tyrosine phosphorylation. This was consistent with the downregulation of phosphorylated EGFR protein expression levels.

In addition, oridonin exhibited a significant growth-inhibition effect on A431 cells. Thus, we speculated that some survival-related signal molecules downstream of EGFR were suppressed by the blockage of EGFR tyrosine phosphorylation, resulting in the growth inhibition of A431 cells.

On the other hand, apoptosis is an essential and highly conserved mode of cell death that is important for normal development, host defense and suppression of oncogenesis. Faulty regulation of apoptosis has been implicated in degenerative conditions, vascular diseases and cancer. ${ }^{41,42)}$ Some anticancer drugs and a variety of cell differentiation inducers have been shown to induce apoptosis in susceptible cancer cells. ${ }^{43,44)}$ Therefore, among the numerous anticancer drugs, which induces both apoptosis and inhibitory effect on tyro- 
sine kinase activity, can inhibit tumor cell growth more effectively. Based on the observation of morphologic changes in cellular nuclei, flowcytometric analysis and oligonucleosomal DNA fragmentation, oridonin, but not genistein, induced A431 cell apoptosis and inhibited tyrosine kinase activity. Thus, the present results may provide a basic view for a further study on the inhibitory effect of oridonin on tyrosine kinase activity.

Taken together, oridonin-induced growth inhibition might be through inhibition of tyrosine kinase activities in A431 cells, and it especially blocked EGFR tyrosine phosphorylation, leading to apoptosis. However, more detailed signaling pathway and other unknown crossways remain to be elucidated.

\section{REFERENCES}

1) Huang J., Wu L. J., Tashiro S. I., Onodera S., Ikejima T., Biol. Pharm. Bull., 28, 2068-2074 (2005).

2) Zhang C. L., Wu L. J., Tashiro S., Onodera S., Ikejima T., Chin. Pharmacol. Bull., 19, 525-529 (2003).

3) Osawa K., Yasuda H., Maruyama T., Morita H., Takeya K., Itokawa H., Phytochemistry, 36, 1287-1291 (1994).

4) Fuji K., Node M., Sai M., Fujita E., Takeda S., Unemi N., Chem. Pharm. Bull., 37, 1472-1476 (1989).

5) Zhang C. L., Wu L. J., Tashiro S. I., Onodera S., Ikejima T., Biol. Pharm. Bull., 27, 1527-1531 (2004).

6) Rucci N., Recchia I., Angelucci A., Alamanou M., Fattore A. D., Fortunati D., Susa M., Fabbro D., Bologna M., Teti A., J. Pharmacol. Exp. Ther, 318, 161-172 ( 2006).

7) Ullrich A., Schlessinger J., Cell, 61, 203-212 (1990).

8) Cantley L. C., Auger K. R., Carpenter C., Duckworth B., Graziani A., Kapeller R., Soltoff S., Cell, 64, 281-302 (1991).

9) Noble M. E. M., Endicott J. A., Johnson L. N., Science, 303, 18001805 (2004).

10) Linassier C., Pierre M., LE PECO J.-B., Pierre J., Biochem. Pharmacol., 39, 187-193 (1990).

11) Shaw R. J., Cantley L. C., Nature (London), 441, 424-430 (2006).

12) Kim H. K., Jeong M. J., Kong M. Y., Han M. Y., Son K. H., Kim H. M., Hong S. H., Kwon B. W., Life Sci., 78, 321-328 (2005).

13) Yamamoto T., Nishida T., Miyajima N., Kawai S., Ooi T., Toyoshima K., Cell, 35, 71-78 (1983).

14) Downward J., Yarden Y., Mayes E., Scrace G., Totty N., Stockwell P., Ullrich A., Schlessinger J., Waterfield M. D., Nature (London), 307, 521-527 (1984).

15) Schlessinger J., Cell, 103, 211-225 (2000).

16) Pawson T., Nash P., Genes Dev., 14, $1027-1047$ (2000).

17) Schlessinger J., Bar-Sagi D., Cold Spring Harb. Sym., 59, 173-179 (1994).
18) Moghal N., Sternberg P. W., Curr. Opin. Cell Biol., 11, 190-196 (1999).

19) Wells A., Int. J. Biochem. Cell Biol., 31, 637-643 (1999).

20) Akiyama T., Ishida J., Nakagawa S., Ogawara H., Watanabe S., Itoh N., Shibuya M., Fukami Y., J. Biol. Chem., 226, 5592-5595 (1987).

21) Levitzki A., Gazit A., Science, 267, 1782-1788 (1995).

22) Levizki A., Biochem. Pharmacol., 40, 913-918 (1990).

23) Akiyama T., Ogawara H., Methods Enzymol., 201, 362-370 (1991).

24) Changa M. S., Chenb B. C., Yuc M. T., Sheud J. R., Chend T. F., Lin C. H., Cell. Signal., 17, 299-310 (2005).

25) Glossman H. P., Presek P., Eigenbrodt E., Arch. Pharmacol., 217, 100-102 (1981).

26) Huang Y. T., Hwang J. J., Lee P. P., Ke F. C., Huang J. H., Huang C. J., Kandaswami C., Middleton J. E., Lee M. T., Brit. J. Pharmacol., 128 , 999-1010 (1999).

27) Wang J., Liu Q. Y., Hu Q. X., Zhang Y., Chin. Pharmacol. Bull., 17, $402-404$ (2001)

28) Mizukami S., Kikuchi K., Higuchi T., Urano Y., Mashima T., Tsuruo T., FEBS Lett., 453, 356-360 (1999).

29) Fujita E., Nagao Y., Kohno T., Matsuda M., Ozaki M., Chem. Pharm. Bull., 29, 3298-3213 (1981).

30) Zhang C. L., Wu L. J., Zuo H. J., Tashiro S. I., Onodera S., Ikejima T., J. Pharmacol. Sci., 96, 155-163 (2004).

31) Nielsen T. O., Hsu F. D., O'Connell J. X., Blake Gilks C., Sorensen P. H. B., Linn S., West R. B., Liu C. L., Botstein D., Brown P. O., Rijn M V. D., Am. J. Pathol., 163, 1449-1456 (2003).

32) Sato K. I., Kimoto M., Kakumoto M., Horiuchi D., Iwasaki T., Tokmakov Alexander A., Fukami Y., Genes Cells, 5, 749-764 (2000).

33) Meuillet E. J., Mania-Farnell B., George D., Inokuchi J. I., Eric G., Exp. Cell Res., 256, 74-82 (2000).

34) Yarden Y., and Sliwkowski M., Nat. Rev. Mol. Cell. Biol., 2, 127-137 (2001).

35) Suresh Babu C. V., Yoon S., Nam H. S., Yoo Y. S., Syst. Biol., 2, 213 221 (2004).

36) Constantinou A., Kiguchi K., Huberman E., Cancer Res., 50, 26182624 (1990).

37) Papazisis K. T., Kalemi T. G., Zambouli D., Geromichalos G. D., Lambropoulos A. F., Kotsis A., Boutis L. L., Kortsaris A. H., Cancer Lett., 233, 255-264 (2006).

38) Blume-Jensen P., Hunter T., Nature (London), 411, 355-365 (2001).

39) Griswold-Prenner I., Carlin C. R., Rosner M. R., J. Biol. Chem., 268, 13050-13054 (1993).

40) Moon W. S., Park H. S., Yu K. H., Park M. Y., Kim K. R., Jang K. Y., Kim J. S., Cho B. H., Hum. Pathol., 37, 1324-1332 (2006).

41) Kerr J. F. R., Winterford C. M., Harmon B. V., Cancer, 73, 20132026 (1994).

42) Han D. K. M., Haudenschild C. C., Hong M. K., Tinkle B. T., Leon M. B., Liau G., Am. J. Pathol., 147, 267-277 (1995).

43) Hicjmann J. A., Cancer Metast. Rev., 11, 121-139 (1992).

44) Chen Z., Naito M., Mashima T., Tsuruo T., Cancer Res., 56, 5224 5229 (1996). 